\title{
Estado actual del sector porcícola del departamento del Quindío en el proceso de adopción de la NIIF para pymes*
}

\author{
Current status of the swine production industry in the \\ Department of Quindío regarding the process of adoption of \\ IFRS for SMES
}

\section{Estado atual do setor suinícola do departamento de Quindío no processo de adoção da NIIF para PME}

\begin{abstract}
Ana Gladys Torres-Castaño
Magíster en Gestión Empresarial, Universidad Libre de Cali. Líder del grupo de investigación la Función Financiera en las Organizaciones, del Departamento del Quindío-GIFIQ. Asesora de investigaciones Universidad del Quindío. Armenia- Colombia. agtorres@uniquindio.edu.co-anagladys68@yahoo.es
\end{abstract}

\section{Deicy Arango-Medina}

Doctorando en Administración de Negocios Universidad AIU - USA. Magíster en Gerencia del Talento Humano, Universidad de Manizales. Docente investigadora grupo de investigación la Función Financiera en las Organizaciones, del Departamento del QunidíoGIFIQ. Armenia- Colombia

darango@uniquindio.edu.co-juandeicy@yahoo.com

\section{Resumen}

El artículo de investigación se enfoca en la obtención de información pertinente y confiable, que aporte estadísticas que definan la condición actual de las empresas del sector porcícola en sus áreas legal, tributaria, administrativa, operativa y contable. La investigación se realiza bajo el método descriptivo para detallar el estado vigente de las empresas, sus características y propiedades. Se utiliza un enfoque mixto, considerando una parte cualitativa dentro de la investigación, dado que existe una referenciación conceptual, teórica y documental, y otra parte cuantitativa, por el uso de métodos estadísticos y tabulación de datos para la presentación de los resultados. Se utilizó como instrumento de recolección de la información una encuesta diseñada para tratar las áreas de la empresa que son pertinentes para la investigación, sobre las cuales se emiten las conclusiones correspondientes.

\footnotetext{
* Cómo citar: Torres-Castaño, A. G., Arango-Medina, D. (2017). Estado actual del sector porcícola del departamento del Quindío en el proceso de adopción de la NIIF para pymes. Revista Libre Empresa, 14(1), 85-110 http://dx.doi.org/10.18041/libemp.2017.v14n1.27104
} 


\title{
Palabras clave
}

Diagnóstico empresarial, sector porcícola, Normas Internacionales de Información Financiera (NIIF) para pymes, departamento del Quindío.

\begin{abstract}
This research article focuses on obtaining relevant, reliable information that provides statistics to define the current status of the legal, tax, administrative, operations, and accounting departments of companies in the swine production industry. Research was conducted using a descriptive method to detail the current status, characteristics, and properties of companies. A combined approach was employed taking into account qualitative aspects as part of research, given that there is a conceptual, theoretical, and documentary reference, and on the other hand, using statistical and data tabulation methods for the presentation of results. A survey designed to address the various areas of companies that are relevant to the research was used as an instrument for gathering information which provided the basis for issuing the conclusions.
\end{abstract}

\section{Keywords}

Business diagnosis, swine production industry, International Financial Reporting Standards (IFRS) for SMEs, Department of Quindío.

\section{Resumo}

O presente artigo de pesquisa enfoca a obtenção de informações relevantes e confiáveis, que forneça estatísticas que definam a condição atual das empresas do setor suinícola em suas áreas legal, tributária, administrativa, operativa e contábil. A pesquisa é conduzida segundo o método descritivo a fim de detalhar o estado vigente das empresas, suas características e propriedades. É usada uma abordagem mista, considerando uma parte qualitativa dentro da investigação dado que existe uma referenciação conceitual, teórica e documental, e outra parte quantitativa, através do uso de métodos estatísticos e tabulação de dados para a apresentação dos resultados. Foi usada como instrumento de coleta de informações uma pesquisa concebida para tratar as áreas da empresa que são pertinentes para a investigação, sobre as quais são emitidas as conclusões correspondentes.

\section{Palavras chave}

Diagnóstico empresarial, setor suinícola, Normas Internacionais de Informação Financeira (NIIF) para PME, departamento de Quindío.

\section{Introducción}

El proceso de adopción de la contabilidad con las Normas Internacionales de Información Financiera (NIIF) para pymes, pone en evidencia las realidades de las empresas y específicamente en el área contable, donde en Colombia se viene trabajando bajo los principios de contabilidad generalmente aceptados descritos en el marco conceptual del Decreto Reglamentario 2649 de 1993, cuyo ámbito de aplicación es para todos los sectores económicos, comerciales, industriales, y de servicios, y se deja establecido 
también que dicha responsabilidad recae directamente sobre la administración de todas las empresas del país.

Las organizaciones empresariales, deben comprender que la adopción de la NIIF para pymes no es solo una actividad de tipo contable, relacionada con cifras, sino que tiene un alcance mayor hacia toda la entidad como tal, incluyendo niveles directivos distintos a la parte financiera, debido a que los alcances interpretativos que deben incluir estas normas determinan aspectos predictivos como la determinación de estimaciones y juicios, así como el análisis del riesgo integral que involucra aspectos cualitativos y cuantitativos que deben informarse al usuario de los estados financieros, afectando tanto las bases de registro de la contabilidad como en los informes o reportes, en los procesos y sistemas de información, en el recurso humano de la organización y los negocios. (ver figura1).
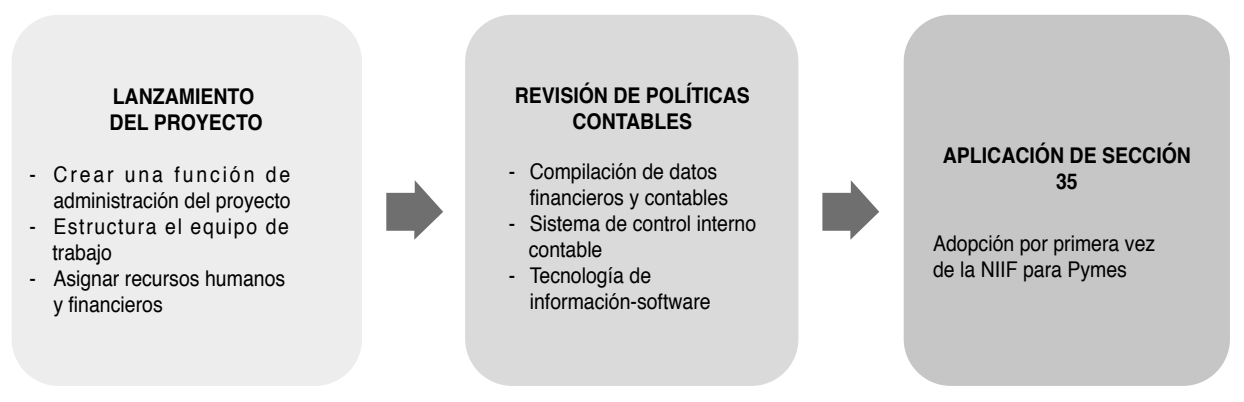

Figura 1. Proceso de adopción de la NIIF para pymes

Fuente: Elaboración propia

Algunos otros aspectos a considerar en el proceso de adopción o conversión a la NIIF para pymes son:

- Los cambios no están restringidos exclusivamente al área financiera-contable, sino al área de impuestos, tecnología de la información, área de recursos humanos, entre otras, de las empresas.

- No solamente es un ejercicio técnico-contable sino que requiere un amplio conocimiento y experiencia en la aplicación del nuevo marco normativo contablefinanciero, expedido bajo el Decreto Reglamentario 3022 de 2013 para las pymes que conforman el grupo 2, que impactará muchas áreas de negocios y las decisiones de los diferentes usuarios como inversionistas, prestamistas, entre otros.

- $\quad$ Las empresas deben esperar cambios en las utilidades y en el patrimonio.

Asimismo, siendo el objetivo final de la conversión a normas internacionales conseguir una mayor transparencia, las empresas deberán proporcionar más información, con mayor frecuencia, a través de los estados financieros, informes y las revelaciones (notas), a tiempo para que sea útil en la toma de decisiones de los diferentes usuarios. 
En la actualidad existe un desconocimiento de las empresas, en especial las pymes, tanto de las Normas Internacionales de Información Financiera (NIIF) como del mismo proceso de convergencia, que deben llevar a cabo al cumplir con los Decretos expedidos por el Gobierno Nacional. Se hace necesario, por lo tanto, asesorar a los empresarios en este caso del sector porcícola del departamento del Quindío, y a sus funcionarios, incluyendo a los Contadores Públicos de las mismas, en el proyecto de convergencia, puesto que en Colombia las entidades de control como las Superintendencias y la DIAN, entre otras, solicitarán información y supervisarán de manera exhaustiva los estados financieros resultado de dicha implementación.

Como punto de partida para este propósito, se planteó el proyecto de investigación "Caracterización de la implementación por primera vez de las Normas Internacionales de Información Financiera (NIIF) para pymes en las empresas del sector agropecuario del departamento del Quindío", cuyo primer objetivo es diagnosticar la situación o estado actual de las empresas pymes que pertenecen a dicho sector; para lo cual se toman como base los sectores platanero, avícola, floricultor y porcícola.

Esta investigación suministra elementos de juicio sobre las condiciones y factores influyentes en el desarrollo de las actividades económicas de dichas empresas, proporcionando un estado real sobre la gestión en los procesos productivos, financieros, aspectos relativos al mercado y los consumidores.

\section{Marco teórico}

\subsection{Diagnóstico empresarial}

En la actualidad, conocer con exactitud el estado en que se encuentran las empresas proporciona obtener una visión más amplia para los usuarios internos y externos permitiendo la toma de decisiones para la gestión concerniente a las necesidades de estos usuarios. Como lo menciona (Arizabaleta, 2000), el diagnóstico empresarial es definido como un proceso de comparaciones entre dos situaciones: la presente que se ha llegado a conocer mediante la indagación, y otra ya definida y supuestamente conocida, que sirve de pauta o modelo. El saldo de esta comparación es lo que se llama diagnóstico.

Los diagnósticos empresariales pueden clasificarse en integrales y específicos (Sergio, 2007), los integrales se caracterizan por la visualización de una alta gama de variables 0 aspectos empresariales, cuya metodología se basa en un estudio de la DOFA, (debilidades, oportunidades, fortalezas y amenazas), según (Salvador \& Ofelia, 1998), este diagnóstico puede denominarse también general, y en esta medida determina de forma macro los puntos débiles financieros y los procesos operativos que requieren una atención inmediata.

$\mathrm{Al}$ realizarse un diagnóstico empresarial se establece un enfoque sobre el cual dirigir todo el trabajo. Aparecen entonces cuatro perspectivas, que ayudan a visualizar la empresa: Perspectiva financiera, perspectiva de los clientes, perspectiva de los procesos internos, y perspectiva de las capacidades del personal y la organización, estas cuatro permiten abarcar aquellos aspectos más importantes del fenómeno empresarial según (Sergio, 2007). 


\subsection{Sector empresarial}

El escenario de competencia en el que la globalización ha dejado a las organizaciones, hace necesario tener entornos empresariales fuertes y con capacidad de adaptarse a todos los cambios que se plantean. Tal fortaleza en las organizaciones no solo se logra con las buenas prácticas gerenciales y su capacidad estructural, si no que se necesita del acompañamiento de agentes externos que contribuyan al crecimiento y fortalecimiento de toda la estructura productiva del país.

Según el Código de Comercio, se entiende por empresa toda actividad económica organizada para la producción, transformación, circulación, administración o custodia de bienes, o para la prestación de servicios. Dicha actividad se realizará a través de uno o más establecimientos de comercio. La empresa es un grupo social en el que, a través de la administración del capital y del trabajo, se producen bienes y/o servicios tendientes a la satisfacción de las necesidades de la comunidad. (Márquez, 2001)

En Colombia, y mientras se reglamenta el artículo 43 de la Ley 1450 de 2011, los parámetros vigentes para clasificar las empresas por su tamaño son los siguientes: (artículo $2^{\underline{0}}$ de la Ley 590 de 2000, modificado por el artículo 2º de la Ley 905 de 2004). Disposición que exige el cumplimiento de las dos condiciones de cada uno de los tipos de empresa.(ver figura 2).

\begin{tabular}{|c|c|}
\hline $\begin{array}{c}\text { MICRO } \\
\text { EMPRESA }\end{array}$ & $\begin{array}{l}\text { - Planta de personal no superior a los diez (10) trabajadores. } \\
\text { - Activos totales excluida la vivienda por valor inferior a quinientos uno (500) salarios mínimos } \\
\text { mensuales legales vigentes. }\end{array}$ \\
\hline $\begin{array}{l}\text { PEQUEÑA } \\
\text { EMPRESA }\end{array}$ & $\begin{array}{l}\text { - Planta de personal entre once (11) y cincuenta (50) trabajadores. } \\
\text { - Activos totales excluida la vivienda por valor inferior a quinientos uno (500) salarios mínimos } \\
\text { mensuales legales vigentes. }\end{array}$ \\
\hline $\begin{array}{l}\text { MEDIANA } \\
\text { EMPRESA }\end{array}$ & $\begin{array}{l}\text { - Planta de personal entre cincuenta y uno (51) y doscientos (200) trabajadores. } \\
\text { - Activos totales por valor entre cinco mil uno (5001) a treinta mil (30.000) salarios mínimos } \\
\text { mensuales legales vigentes. }\end{array}$ \\
\hline $\begin{array}{c}\text { GRAN } \\
\text { EMPRESA }\end{array}$ & - Las demás que no cumplan con los anteriores requisitos. \\
\hline
\end{tabular}

Figura 2. Clasificación de las empresas según su tamaño

Fuente: Ley 905 de 2004

\subsection{Sector porcícola}

Conjunto de cerdos criados para su explotación. El cerdo es un animal mamífero que puede encontrarse en estado salvaje o doméstico. El nombre científico de la especie 
en estado natural es Sus scrofa y los ejemplares que han sido domesticados reciben el nombre de Sus scrofa doméstica. Se trata de un cuadrúpedo con patas cortas y pezuñas, un cuerpo pesado, hocico flexible y cola corta.

El cerdo se ha seleccionado a través de los años por su velocidad de crecimiento y el aprovechamiento de los alimentos (con una conversión de 2-3 kilos alimento por 1.5 kilos de carne, el segundo luego de las aves). Es un animal a piel desnuda, cubierta solamente por cerdas, sin glándulas sudoríparas funcionales, por lo que no se defiende bien ante elevadas temperaturas.

Es la especie más prolífica de todas las medianas y de gran tamaño, normalmente la cerda pare entre 8 y 12 lechones; dependiendo de las razas las chinas pueden llegar a los 22 lechones y los 2 partos anuales, pueden aparearse durante todo el año, la gestación dura 114 días y la lactancia puede variar entre 3- 4 semanas, según el manejo aplicado.

Actualmente en Colombia la porcicultura tecnificada se encuentra distribuida de la siguiente manera: casi la mitad de las granjas están ubicadas en el departamento de Antioquia con el $49.3 \%$ del total, las otras regiones que le siguen en número, tienen una participación mucho más baja, que apenas alcanza el 15.4\% en la región central (Cundinamarca, Huila y Tolima), el 13.6\% en el Valle del Cauca y Cauca, 11\% en la región oriental (Santander, Boyacá, Meta y Casanare) y 7\% en la región cafetera (Caldas, Quindío y Risaralda). La participación más baja corresponde a la Costa Atlántica, con tan sólo el 4.1\% de las granjas (Sociedad de Agricultores de Colombia, 2002).

\subsection{Normas Internacionales de Información Financiera (NIIF) para pymes,}

Según el IASB, la NIIF para las pymes es una norma autónoma de 230 páginas, diseñadas para satisfacer las necesidades y capacidades de las pequeñas y medianas empresas (Pyme), que se estima representan más del $95 \%$ de las empresas de todo el mundo.

La NIIF para las pymes establecen los requerimientos de reconocimiento, medición, presentación e información a revelar que se refieren a las transacciones y otros sucesos y condiciones que son importantes en los estados financieros con propósito de información general. También pueden establecer estos requerimientos para transacciones, sucesos y condiciones que surgen principalmente en sectores industriales específicos. La NIIF se basa en un marco conceptual, que se refiere a las nociones presentadas dentro de los estados financieros con propósito de información general. Para las pymes es de gran importancia conocer sobre la aplicabilidad de la NIIF. En comparación con la NIIF completa (y muchos PCGA nacionales), la NIIF para las pymes son menos complejas en una serie de formas para tratar ciertos eventos y transacciones en los estados financieros.

El Consejo Técnico de la Contaduría Pública expidió el 5 de diciembre de 2012, el documento denominado "Direccionamiento Estratégico", el cual deja explícita la clasificación de las empresas para la adopción de las normas internacionales (ver Tabla1) 


\section{Tabla 1.}

Clasificación de las empresas para la adopción de Normas Internacionales

\begin{tabular}{|c|c|}
\hline 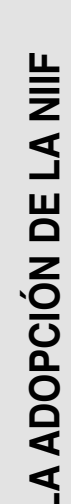 & $\begin{array}{l}\text { a) Emisores de valores; b) Entidades de interés público; c) Entidades que tengan } \\
\text { Activos totales superiores a treinta mil }(30,000) \text { SMMLV o planta de personal } \\
\text { superior a doscientos (200) trabajadores; que no sean emisores de valores ni } \\
\text { entidades de interés público y que cumplan además cualquiera de los siguientes } \\
\text { requisitos: I. ser subordinada o sucursal de una compañía extranajera que aplique } \\
\text { NIIF; II. Ser subordinada o matriz de una compañía nacional que deba aplicar } \\
\text { NIIF; III. Realizar importaciones (pagos al exterior, si se trata de una empresa } \\
\text { de servicios) o exportaciones (ingresos del exterior, si se trata de una empresa } \\
\text { de servicios) que representen más del } 50 \% \text { de las compras (gastos y costos, si } \\
\text { se trata de una empresa de servicios) o de las ventas (ingresos, si se trata de } \\
\text { una compañia de servocios), respectivamente, del año inmediatamente anteior al } \\
\text { ejercicio sobre el que se informa, o IV. Ser matriz, asociada o negocio conjunto de } \\
\text { una o más entidades extranjera que apliquen NIIF. }\end{array}$ \\
\hline
\end{tabular}

a) Empresas que no cumplan con los requisitos del literal c) del grupo 1 ; b) Empresas que tengan Activos totales por valor entre quinientos (500) y treinta mil (30.000) SMMLV o planta de personal entre once (11) y doscientos (200) trabajadores, y que no sean emisores de valores ni entidades de interés público; y c) Microempresas que tengan Activos totales excluida la vivienda por un valor máximo de quinientos (500) SMMLV o Planta de personal no superior a los diez (10) trabajadores, y cuyos ingresos brutos anuales sean iguales o superiores a 6.000 SMMLV. Dichos ingresos brutos son los ingresos correspondientes al año inmediatamente anterior al periodo sobre el que se informa. Para la clasificación de aquellas empresas que presenten combinaciones de parámetros de planta de personal y activos totales diferentes a los indicados, el factor determinante para dicho efecto, será el de activos totales.

a) Personas naturales o jurídicas que cumplan los criterios establecidos en el art. 499 del Estatuto Tributario (ET) y normas posteriores que lo modifiquen. Para el efecto, se tomará el equivalente a UVT, en salarios mínimos legales vigentes. (b) Microempresas que tengan Activos totales excluida la vivienda por un valor máximo de quinientos (500) SMMLV o Planta de personal no superior a los diez (10) trabajadores que no cumplan con los requisitos para ser incluidas en el grupo 2 ni en el literal anterior.

Fuente: Consejo Técnico de la Contaduría Pública, 2012

\subsection{Departamento del Quindío}

El departamento del Quindío ha modificado drásticamente su estructura económica y productiva, pasando de ser un departamento donde el sector agropecuario aportaba el 33.15\% del PIB total en 1990 a 18.86\% para el 2005 (Gobernación del Quindío, 2008). 
Este cambio debe estar dado principalmente por la crisis cafetera, pero en lo que tiene que ver con el sector porcícola los datos muestran un sector que ha crecido y se ha formalizado. Para el año 2010 el Quindío presentaba un índice de formalidad del 0,65 que comparado con otras regiones es muy favorable. El Quindío para datos estadísticos según el DANE se encuentra dentro de la región occidental compuesta por Quindío, Risaralda, Caldas y Valle del Cauca y presenta las siguientes características:

Del total de las granjas porcícolas tecnificadas presentes en esta región la mayoría se dedican al ciclo completo de producción lo que significa que las crías nacen en sus granjas y están allí hasta cuando están aptas para el sacrificio (cría, levante y ceba). Es un sector que utiliza principalmente recursos propios para el desarrollo de su actividad. La comercialización final es realizada en gran medida por intermediarios. (Datos tomados directamente de información proporcionada por las empresas, 2016)

En cuanto al consumo, el departamento del Quindío para el año 2011 presentó un consumo per- cápita de 4,4 kg, por debajo del promedio nacional que para el 2011 era de 5,17 kg. Por otro lado, los datos de sacrificio para el departamento mostraron una variación favorable entre el segundo trimestre de 2014 y el mismo periodo del 2015, pasando de 11.495 cerdos sacrificados a 14.190 sacrificios, en que da una variación porcentual del 27\%. Esta variación tan representativa muestra no solo un aumento en la producción de porcinos, sino también un aumento en el grado de formalización del sector en la región.

\section{Metodología}

A nivel de enfoque epistemológico la investigación es empírico analítica, toda vez que este tipo de investigación asume el análisis de aspectos positivistas siendo estos los resultados desde variables de tipo financiero y de gestión de las organizaciones. El propósito de la investigación lo ubica en el contexto del análisis de una realidad económica del país, para verificar las nuevas tendencias en la preparación y presentación de la información financiera por parte de las empresas clasificadas como pymes del sector porcícola del departamento del Quindío, que se verán afectadas con la aplicación de la Ley 1314 de 2009 de convergencia, El conocimiento a producir es formal y esta sujeto a las variables consideradas, las cuales serán indicadores de carácter cuantitativo.

- Enfoque disciplinar: Empírico Analítica, toda vez que pretende revelar las relaciones esenciales y las características fundamentales del objeto de estudio, por medio de procedimientos prácticos. En su primera fase, la investigación al ser eminentemente documental presentará aspectos que referencien el nivel descriptivo e interpretativo de los mismos.

- Tipo de investigación: Cualitativa, Cuantitativa, a través de la investigación se realizará un estudio para el cumplimiento de la implementación de la NIIF para pymes en las empresas del sector porcícola del departamento del Quindío.

- Técnicas: Entrevistas y encuestas estructuradas, análisis documental de los Decretos Reglamentarios, Normas Internacionales de Información Financiera NIIF para Pymes, 
documentos expedidos por el IASB como guías e interpretaciones, y evaluación de estados financieros. Construcción de indicadores financieros y de gestión y aplicación de matrices de análisis.

- Unidad de análisis: Las empresas pymes del sector porcícola del departamento del Quindío, registradas en Cámara de Comercio a 31 de marzo de 2016. Al realizar la correspondiente depuración, se obtuvo un total de siete (7) empresas aptas para la aplicación del instrumento. Según la localización de las empresas que fueron objeto de la encuesta, se pudo determinar que los sectores rurales de los municipios de Circasia y Calarcá, es donde más se ha desarrollado la industria porcícola en el departamento. Del total de las empresas encuestadas, tres están ubicadas en zona rural del municipio de Circasia, dos en la zona cordillerana de Calarcá y dos en el municipio de Armenia.

\section{Resultados de la investigación}

El presente diagnóstico empresarial, evidencia el estado actual de las pymes que pertenecen al sector porcícola en el departamento del Quindío; a través de la información obtenida se puede determinar de manera contundente las posibles fallas y áreas que están siendo ineficientes, de igual manera pueden destacarse aquellas áreas en las que la empresa está haciendo su gestión de manera asertiva y eficaz.

\subsection{Información legal y tributaria}

El objeto de las pymes del sector porcícola en el departamento del Quindío está dirigido a la producción de lechones para su venta, desde su nacimiento hasta lograr un peso estimado para su comercialización. Las empresas deben operar bajo los lineamientos fiscales, de acuerdo con el régimen al cual pertenecen, contemplando las obligaciones tributarias establecidas a través de esta categorización. (ver figura 3).

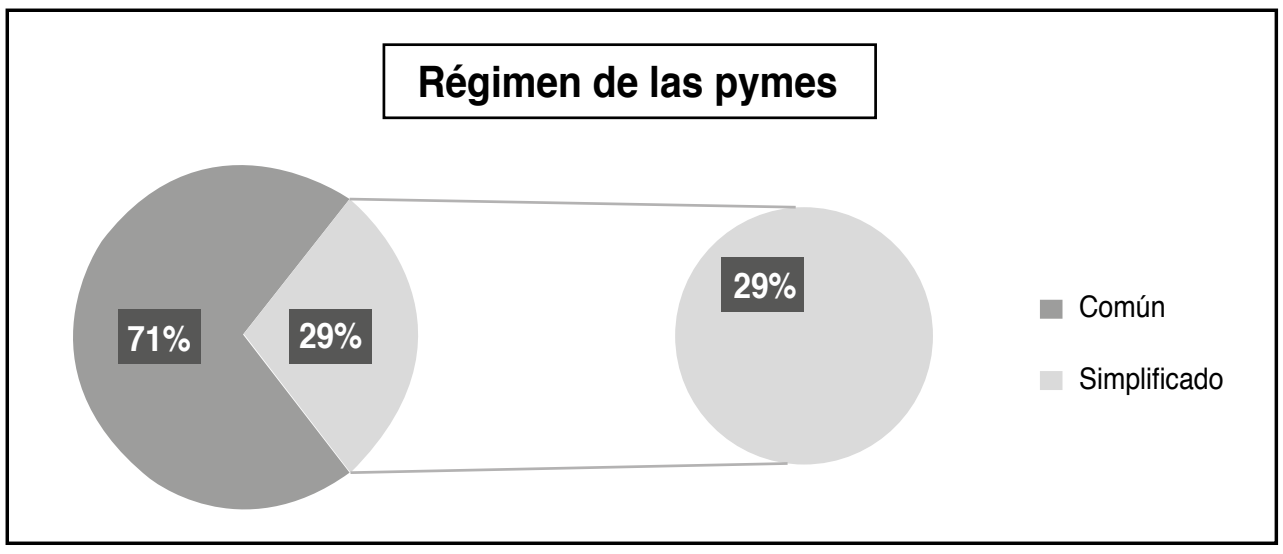

Figura 3. Régimen al que pertenecen las pymes del sector porcícola.

Fuente: Elaboración propia a partir de la encuesta realizada a las pymes del sector porcícola en el departamento del Quindío. 
La figura anterior muestra que el $71 \%$ de las pymes pertenecen al régimen común y el 29\% al régimen simplificado, lo que evidencia que el sector tiene un grado de formalidad muy representativo.

En lo referente al grupo al que pertenecen las empresas según el marco normativo, se encontró lo siguiente. (ver figura 4).

\section{Grupo al que pertenecen las pymes}

150

100

50

0

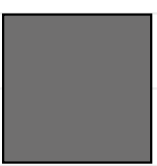

Grupo I Dec. 2784/2012

Grupo II Dec. 3022/2013

Grupo III Dec. 2706/2012

Figura 4. Grupo al que pertenecen las empresas según los marcos normativos

Fuente: Elaboración propia, a partir de la encuesta realizada a las empresas del sector porcícola en el departamento del Quindío.

Según la clasificación de las empresas para la adopción de las Normas Internacionales de Información Financiera (NIIF) para pymes, según la figura anterior, se encontró que el $100 \%$ de las pymes pertenecen al Grupo 2 .

Con respecto al cumplimiento de obligaciones de tipo legal y tributario, la potestad que tienen las empresas para desarrollar sus actividades económicas, se facultan a través de cada uno de los documentos legales que acreditan y permiten su ejercicio, (ver figura 5).

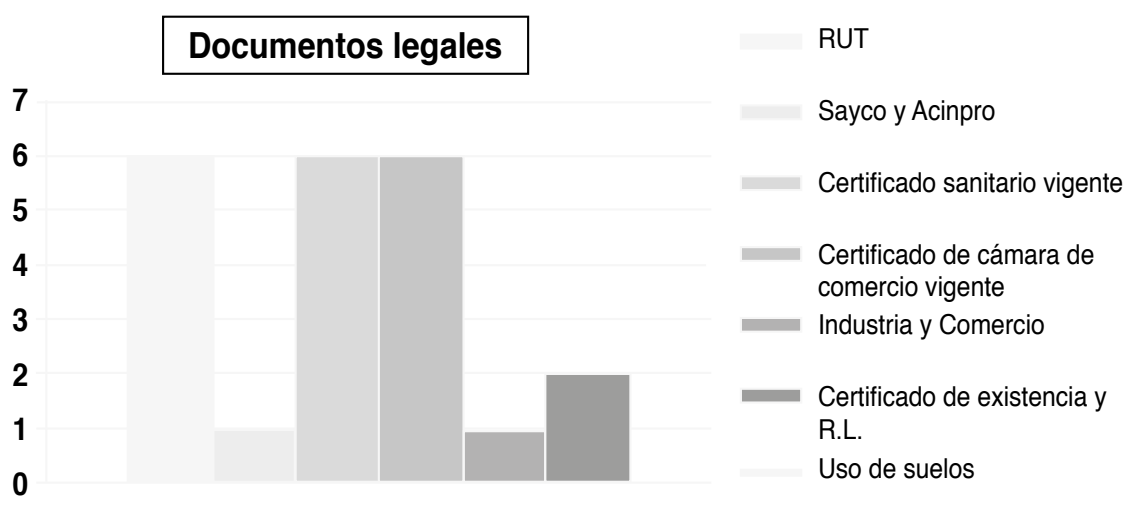

Figura 5. Cumplimiento de obligaciones legales y tributarias

Fuente: Elaboración propia a partir de la encuesta realizada a las pymes del sector porcícola en el departamento del Quindío. 
Se evidencia que las empresas no tienen todos los documentos legales requeridos para el ejercicio de sus actividades. El 86\% de las mismas poseen RUT, certificado sanitario vigente, certificado Cámara de Comercio vigente, y uso de suelos. Sólo el 29\% de las empresas encuestadas cuenta con el certificado de existencia y representación legal, el registro bomberil y el registro de libros de comercio. Los documentos que se encuentran en menor proporción son los de Sayco y Acinpro, industria y comercio y el de avisos y tableros.

En lo concerniente a las formas jurídicas previstas en la legislación de nuestro país para la constitución de las organizaciones empresariales, se encontró el siguiente resultado (ver figura 6).

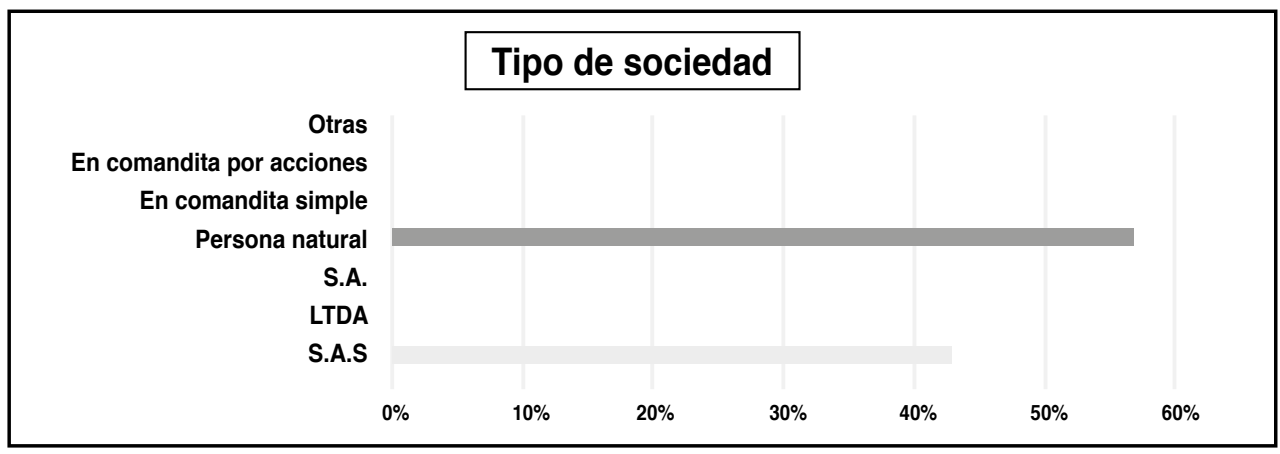

Figura 6. Tipo de sociedad

Fuente: Elaboración propia a partir de la encuesta realizada a las pymes del sector porcícola en el departamento del Quindío.

Según la figura anterior, el $43 \%$ de las empresas son S.A.S., y el 57\% restante se ubica en la categoría de persona natural, lo que implica que las unidades empresariales del sector porcícola prefieren no conformar sociedades de varias personas o dueños.

En lo referente a la relación que existe entre las empresas con otras a través de grupos empresariales se evidencia en la Figura 7.

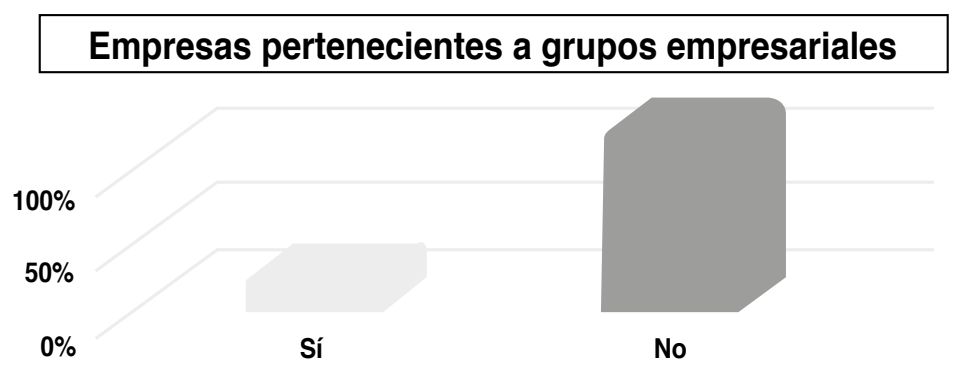

Figura 7. Empresas pertenecientes a grupos empresariales

Fuente: Elaboración propia, a partir de la encuesta realizada a las pymes del sector porcícola en el departamento del Quindío. 
El 14\% de las empresas del sector porcícola del departamento del Quindío pertenecen a grupos empresariales, tienen relaciones con matrices, subsidiarias, filiales o sucursales, con vinculados económicos o partes relacionadas, y el 86\% restante no tiene relaciones de este tipo con otras empresas:

Dentro de la información solicitada a las empresas que es pertinente para el desarrollo de esta investigación incluye el área tributaria donde se indica lo siguiente (ver figura 8).

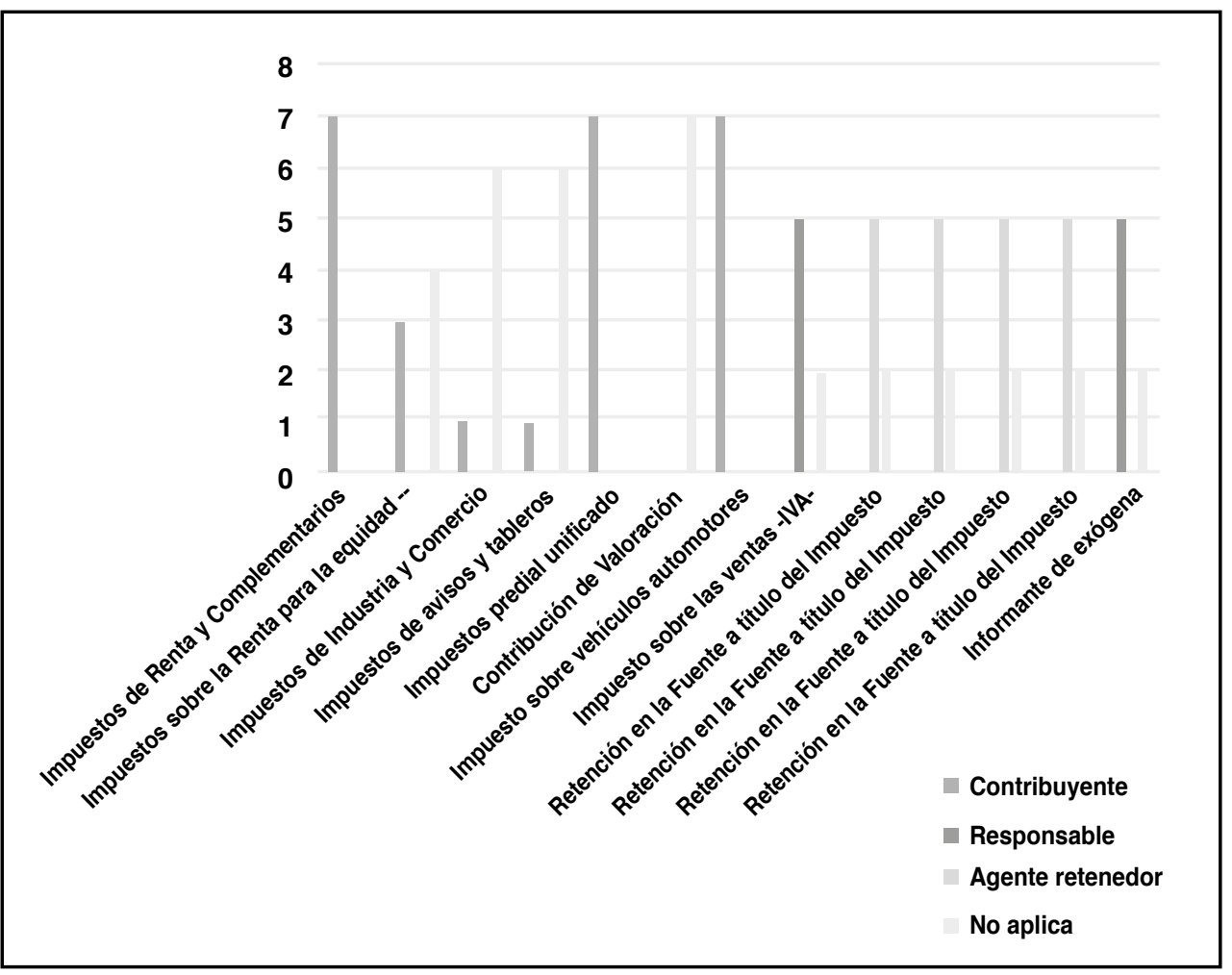

Figura 8. Área tributaria de las pymes que pertenecen al sector porcícola

Fuente: Elaboración propia, a partir de la encuesta realizada a las pymes del sector porcícola en el departamento del Quindío.

En relación en los impuestos sobre los cuales las empresas tienen responsabilidad se encontró que en el caso del impuesto de renta y complementarios, el 100\% de las empresas son contribuyentes, para el impuesto sobre la renta para la equidad-CREE- el $43 \%$ son contribuyentes y para el 57\% restante no aplica. Para el impuesto de industria y comercio, al igual que el impuesto de avisos y tableros se tiene que el 14\% de las empresas son contribuyentes de estos y para el 86\% de ellas no aplica, el porcentaje es el mismo dado que los dos impuestos se pagan de manera conjunta. Con respecto al impuesto predial unificado el 100\% de las empresas son contribuyentes del mismo, todo lo contrario pasa con 
la contribución de valorización donde para ninguna de las empresas aplica. Por otro lado el $100 \%$ de los encuestados son contribuyentes del impuesto de vehículos automotores. En cuanto al impuesto, sobre las ventas-IVA- el $71 \%$ de las empresas encuestadas son responsables del impuesto mientras que para el $29 \%$ restante no aplica. Las empresas con respecto a la retención en la fuente a título del impuesto de renta, retención en la fuente a título del impuesto de IVA, retención en la fuente a título del impuesto de industria y comercio y retención en la fuente a título del impuesto para la equidad CREE, el $71 \%$ de ellas son agentes retenedores, mientras que el $29 \%$ adicional no aplica. Finalmente en lo concerniente a ser informantes de exógena, el $71 \%$ son responsables y para el $29 \%$ no aplica.

Del área legal y tributaria se puede destacar el hecho de que solo una empresa pertenece a un grupo empresarial y que la mayoría de ellas son personas naturales, de lo que se puede inferir que el sector porcícola del departamento administrativamente presenta estructuras poco complejas.

En lo referente al hecho de que las empresas se encuentran bajo la inspección, vigilancia o control de alguna superintendencia, se obtuvieron los siguientes resultados (figura 9).

\section{Empresas bajo inspección de alguna superintendencia}

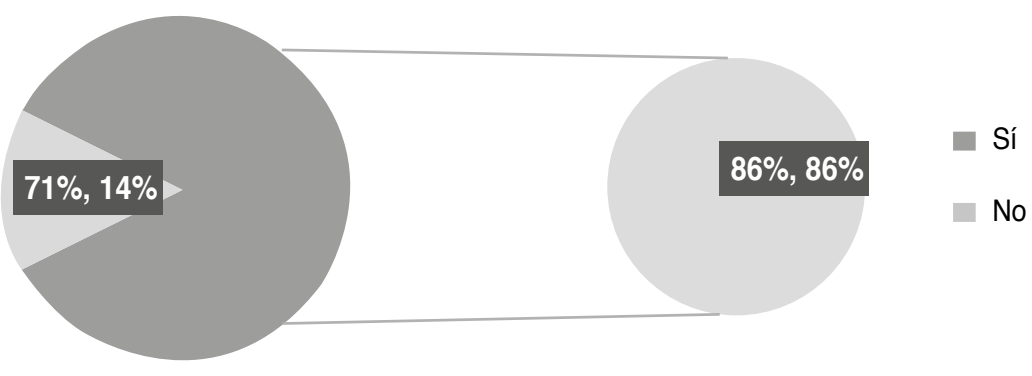

Figura 9. Empresas bajo inspección de alguna Superintendencia

Fuente: Elaboración propia, a partir de la encuesta realizada a las pymes del sector porcícola en el departamento del Quindío

Se destaca que tan solo el 14\% está bajo supervisión para el caso de la Superintendencia de Sociedades, mientras que el $86 \%$ restante no.

Con la entrada en vigencia de los nuevos requerimientos contables que están enmarcados dentro de la Ley 1314 de 2009, se pretendió conocer si las empresas están relacionadas con el tema y si tienen conocimiento de ello ( Ver Figura 10). 


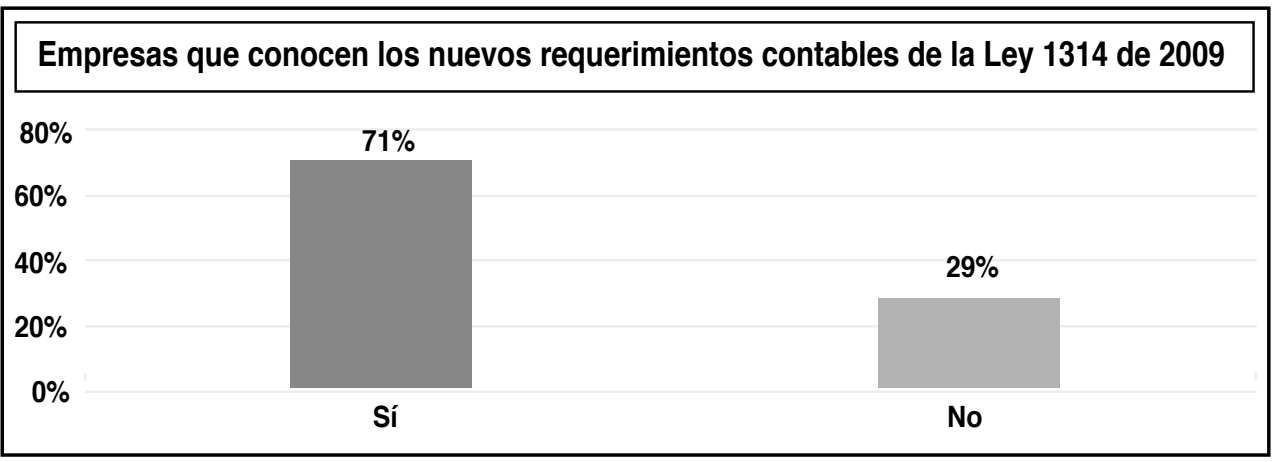

Figura 10. Empresas que conocen los nuevos requerimientos contables de la ley 1314 de 2009

Fuente: Elaboración propia, a partir de la encuesta realizada a las pymes del sector porcícola en el departamento del Quindío.

El 71\% de las empresas tienen conocimientos de la entrada en vigencia de la Ley 1314 de 2009, aunque manifestaron que la aplicación de tales normas se ha realizado de manera pausada dado que tienen dificultad al momento de aplicarlas, el 29\% sobrante no conocen de éstos requerimientos. Adicionalmente, se indagó si alguna Superintendencia les ha exigido un plan de implementación de la NIIF, dado que esta ley ya está vigente, y hasta el momento a ninguna de ellas se les ha requerido un plan para ese proceso.

De otro lado, existen unos tipos de ayuda que el Gobierno Nacional ofrece a las empresas para contribuir al buen desarrollo de sus actividades, se investigó si éstas reciben algún tipo de subvención y el 100\% de las empresas encuestadas no reciben ningún tipo de ayuda por parte del Estado.

\subsection{Información administrativa y contable}

Con el propósito que se tiene de conocer el estado actual de las pymes que pertenecen al sector porcícola en el departamento del Quindío, se hizo énfasis en las áreas administrativas y contables, dado que allí se forjan los objetivos, se trazan las metas y estrategias, se coordinan e integran las actividades, además que se opera toda la parte de control y seguimiento al buen desarrollo y funcionamiento de la organización. (Ver Figura 11).

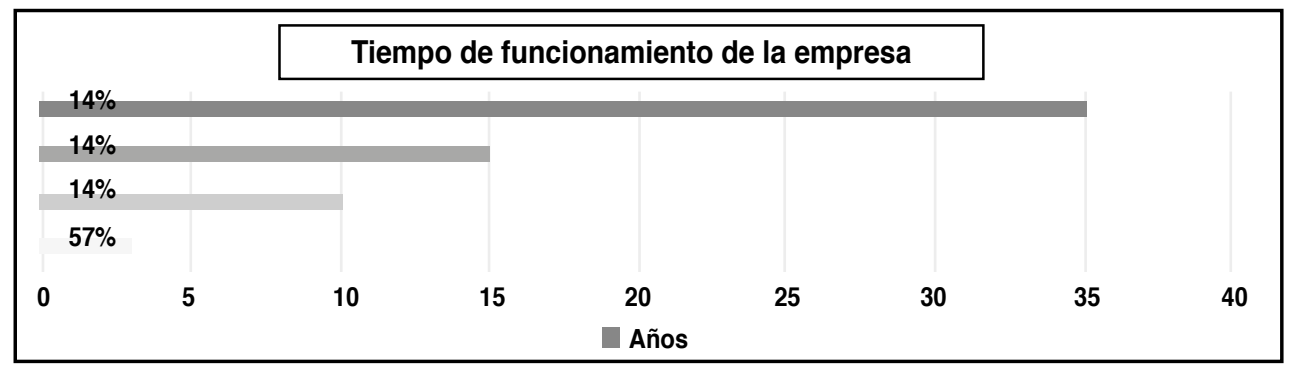

Figura 11. Tiempo de funcionamiento de la empresa

Fuente: Elaboración propia, a partir de la encuesta realizada a las pymes del sector porcícola en el departamento del Quindío 
Se puede observar que un $57 \%$ de las empresas llevan 3 años de haber iniciado sus actividades económicas en el mercado, 14\% de ellas comenzaron labores hace 10 años, otro 14\% inició hace 15 años y finalmente el 14\% restante lleva 35 años en el mercado. Puede entenderse que la actividad porcícola en el Quindío viene desarrollándose desde hace muchos años, sin embargo ha habido más crecimiento en los últimos años.

Complementado esta información se indagó, si las empresas cuentan con una certificación de calidad. (Ver Figura 12).

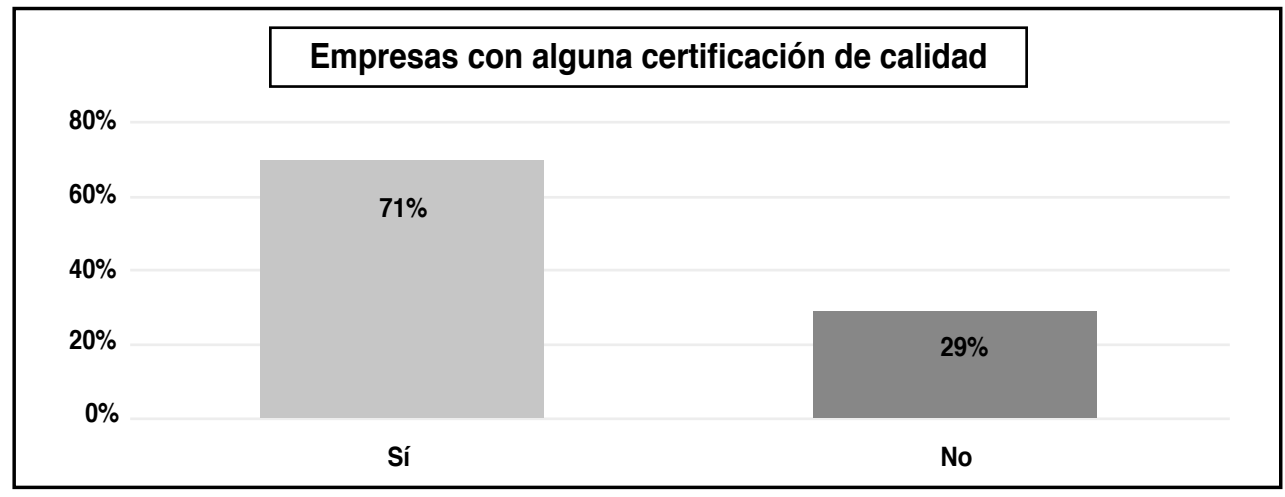

Figura 12. Empresas con certificación de calidad

Fuente: Elaboración propia a partir de la encuesta realizada a las pymes del sector porcícola en el departamento del Quindío

Un 71\% de las empresas cuenta con certificación de calidad, en este caso coincide que las empresas obtuvieron el certificado BPG ( Buenas Prácticas Ganaderas) que otorga el ICA (Instituto Colombiano Agropecuario) a los ganaderos por ofrecer productos con garantía sanitaria y de inocuidad que no generan riesgos para la salud humana. El 29\% restante no posee ningún tipo de certificación de calidad.

En lo relacionado en el cumplimiento de obligaciones de tipo laboral de acuerdo con las exigencias legales, se encontró que el 100\% de las empresas cumplen con las obligaciones de ley con el pago a sus empleados, cabe destacar que este hecho tiene una incidencia directa en el rendimiento de los empleados y contribuye al buen desarrollo de la organización.

Con respecto al área contable, se indagó si las empresas del sector porcícola del departamento del Quindío están obligadas a llevar contabilidad, y dan cumplimiento a esta exigencia. (Ver Figura 13). 


\section{Empresas obligadas a llevar contabilidad}

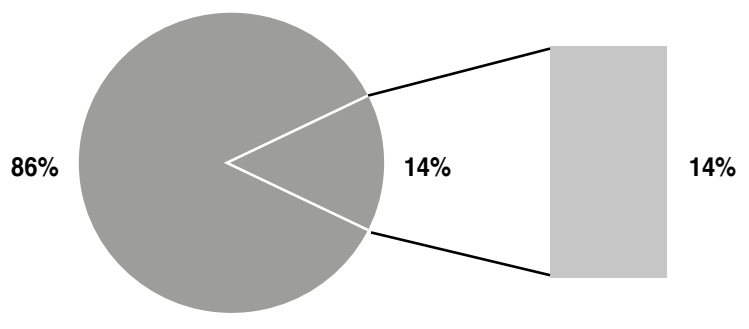

Figura 13. Empresas obligadas a llevar contabilidad

Fuente: Elaboración propia a partir de la encuesta realizada a las pymes del sector porcícola en el departamento del Quindío

Como se evidencia, el $86 \%$ de las empresas están cumpliendo con el requerimiento y la obligación de llevar contabilidad, todo lo contrario ocurre con el 14\% restante de las empresas que no practican el ejercicio contable, dejando a la deriva el control de la organización, ya que la contabilidad permite conocer la realidad económica y financiera de una empresa, teniendo un conocimiento global de ella, como su funcionamiento, evolución, presente e incluso su futuro. Es un mecanismo de control por excelencia, pues es el indicador que permite administrar correctamente el patrimonio de la empresa.

Dentro de esta área existen ciertos parámetros que encaminan a la organización a actuar de manera determinada frente a distintas situaciones, estas son las políticas contables. Al preguntar a las empresas acerca de si poseen un manual de políticas contables, tan solo el $14 \%$ de ellas lo tienen. Cabe resaltar que la implementación de un manual de políticas contables rige el curso de las operaciones y transacciones que se realicen dentro de la empresa y permite adecuarse a las necesidades o propósitos que tiene la organización.

En relación con lo anterior, se quiso conocer la autoridad que avala las políticas contables dentro de la organización, y se demostró que es el administrador con un porcentaje de $100 \%$ la persona que se encarga de aprobar las políticas contables que rigen la empresa.

Igualmente, es imprescindible para las empresas el uso de un software contable para el procesamiento de la información financiera que facilite la contabilidad de la empresa, que genere reportes oportunos y actualizados para la toma de decisiones en determinadas circunstancias. (Ver Figura 14). 


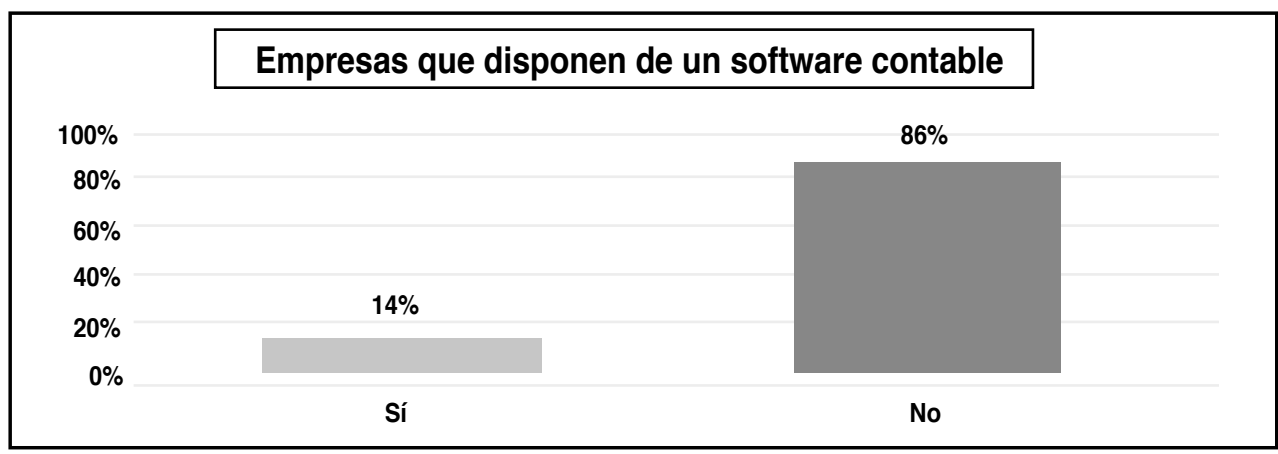

Figura 14. Empresas que disponen de software contable

Fuente: Elaboración propia, a partir de la encuesta realizada a las pymes del sector porcícola en el departamento del Quindío

Se identifica que el $86 \%$ de las empresas no poseen un software contable y que solo el $14 \%$ de ellas tiene uno, cabe mencionar que las empresas no cuentan con un software adicional de apoyo. En definitiva, las empresas que no poseen este tipo de recursos pueden presentar desventaja competitiva frente a las demás.

En cuanto al funcionario que se encarga de elaborar los reportes contables, se estableció que el $86 \%$ de las empresas tienen como funcionario encargado de generar los reportes contables al Contador Público, la persona más competente e idónea para esta labor, para el $14 \%$ restante de las empresas no aplica. Se resalta el hecho que en la mayoría de las empresas tienen muy claro el papel del Contador Público en el desarrollo del ejercicio contable.

Las empresas agrupan las subcuentas que representan medios de pago como dinero en efectivo, cheques, giros, entre otros, así como los depósitos en instituciones financieras. (Ver Figura 15).

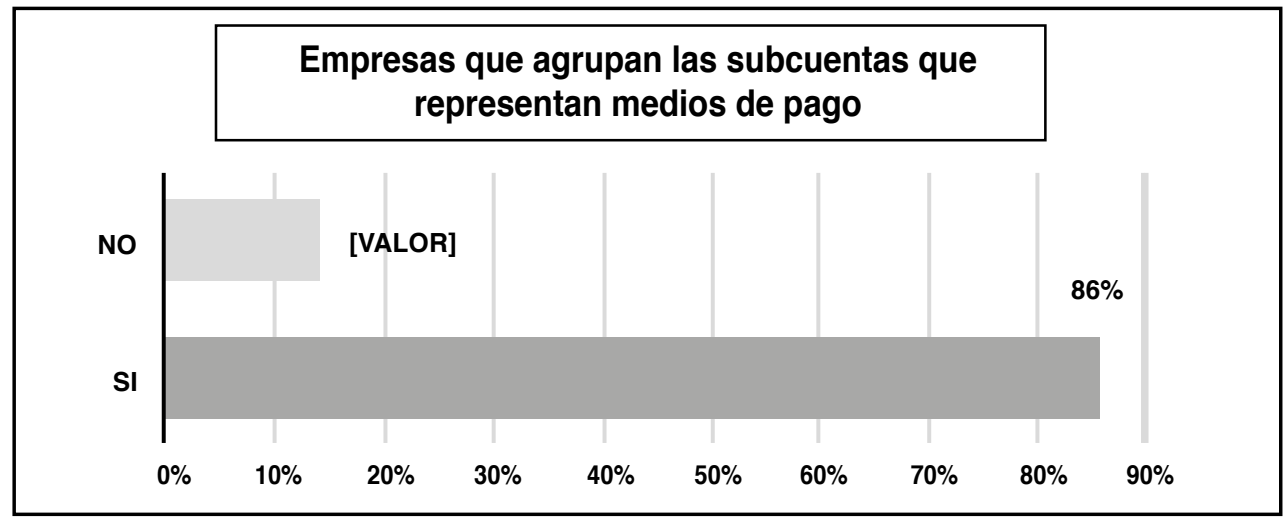

Figura 15. Empresas que agrupan las subcuentas que representan medios de pago

Fuente: Elaboración propia, a partir de la encuesta realizada a las pymes del sector porcícola en el departamento del Quindío 
Se observa que el $86 \%$ de las empresas encuestadas agrupan las subcuentas que representan medios de pago, mientras que el $14 \%$ no lo hace. En relación con las empresas que reconocen las transacciones al valor nominal, se tiene que el mismo porcentaje de empresas lo hacen, teniendo en cuenta que cuando se habla de valor nominal es aquel que figura escrito en el título o valor.

Con respecto al manejo que le dan las empresas del sector porcícola en el departamento del Quindío al disponible, se indagó si existe algún tipo de restricción para esta cuenta, y se determinó que el 100\% de las mismas no presenta ningún tipo de restricción, esto responde a una de las características del sector en el departamento que menciona que estas unidades empresariales se financian principalmente con recursos propios.

En lo que respecta al reconocimiento de los sobregiros bancarios en el balance general, según las conciliaciones bancarias se obtuvo el resultado presentado en la Figura 16.

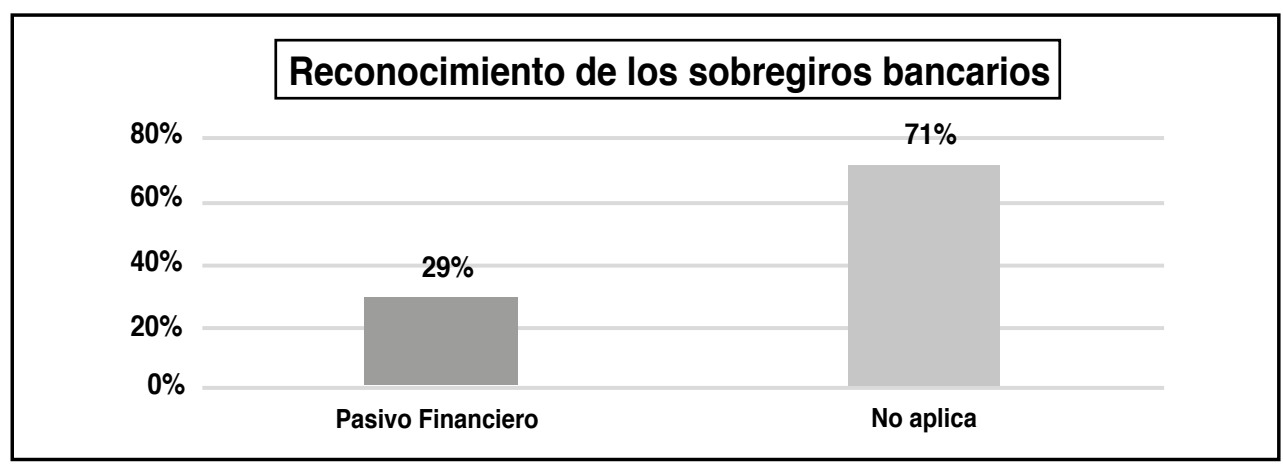

Figura 16. Reconocimiento de los sobregiros bancarios

Fuente: Elaboración propia a partir de la encuesta realizada a las pymes del sector porcícola en el departamento del Quindío

Según se indica el 29\% de las empresas reconocen los sobregiros bancarios en el balance general como un pasivo financiero, mientras que para el $71 \%$ restante no aplica.

Se indagó además la manera como se registra la adquisición de inversiones en instrumentos financieros básicos clasificados, y se obtuvo que el 57\% de las empresas encuestadas registran las adquisiciones al costo, para el $43 \%$ restante no aplica. Además, el $86 \%$ de las pymes hacen el reconocimiento inicial de los instrumentos financieros al valor razonable entre tanto para el 14\% restante no aplica. Igualmente el 29\% de las empresas no realizan esta medición de las inversiones en acciones al valor razonable después de su reconocimiento inicial y para el 71\% restante no aplica, en razón a que estas empresas no realizan inversiones.

Adicionalmente, se observó si las empresas tienen inversiones sin un precio de mercado activo y cuyo valor razonable no puede ser medido con fiabilidad y por tal razón su medición se ha hecho al costo amortizado. (Ver Figura 17). 


\section{Inversiones en acciones con precio de mercado inactivo que se han medido al costo amortizado}

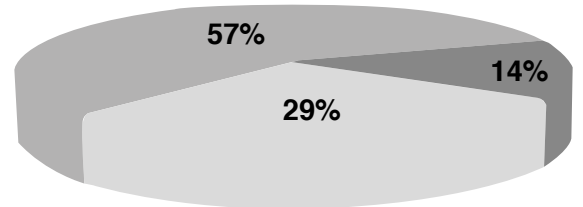

Figura 17. Inversiones en acciones con precio de mercado inactivo que se han medido al costo amortizado Fuente: Elaboración propia a partir de la encuesta realizada a las pymes del sector porcícola en el departamento del Quindío

El 14\% de las empresas han medido las acciones al costo amortizado, el 29\% no lo realiza y para el $57 \%$ restante no aplica este procedimiento. También se tuvo presente el hecho de reconocer la pérdida por deterioro del valor de las inversiones cuando han sido medidas, y el 43\% de las empresas reconocen la pérdida por deterioro del valor de las inversiones, no aplica para el otro $57 \%$ restante.

Adicionalmente se quiso saber si las partidas que agrupan las cuentas por cobrar a clientes, se reconocen inicialmente al precio de la transacción, es decir, al valor razonable, y el $86 \%$ de las empresas lo hacen, para el 14\% restante no aplica. Además el $86 \%$ de las empresas encuestadas no realizan la corrección en libros cuando se presenta un deterioro de las cuentas por cobrar, mientras que para el $14 \%$ adicional no aplica. En cuanto a si las empresas poseen anticipos y avances en este rubro, el 29\% de ellas lo hacen, el $43 \%$ no los manejan y para el $29 \%$ restante no aplica.

En lo referente a un sistema de inventario y qué tipo de sistema se utiliza, ninguna de las empresas ha implementado un sistema de inventarios, lo que puede dificultar conocer con exactitud la entrada y salida de productos, además de no poder tener datos exactos de consumo y existencias. Igualmente, el $86 \%$ de las empresas registran todos los costos de adquisición para que el inventario tenga su condición y ubicación actual, mientras que el $14 \%$ no lo hace, y adicionalmente las empresas no utilizan ninguna fórmula de costo para la salida de sus inventarios.

En relación con la productividad de las empresas, al momento de estar disponible para la venta, es necesario conocer si esta se mide al valor razonable. (Ver Figura 18). 


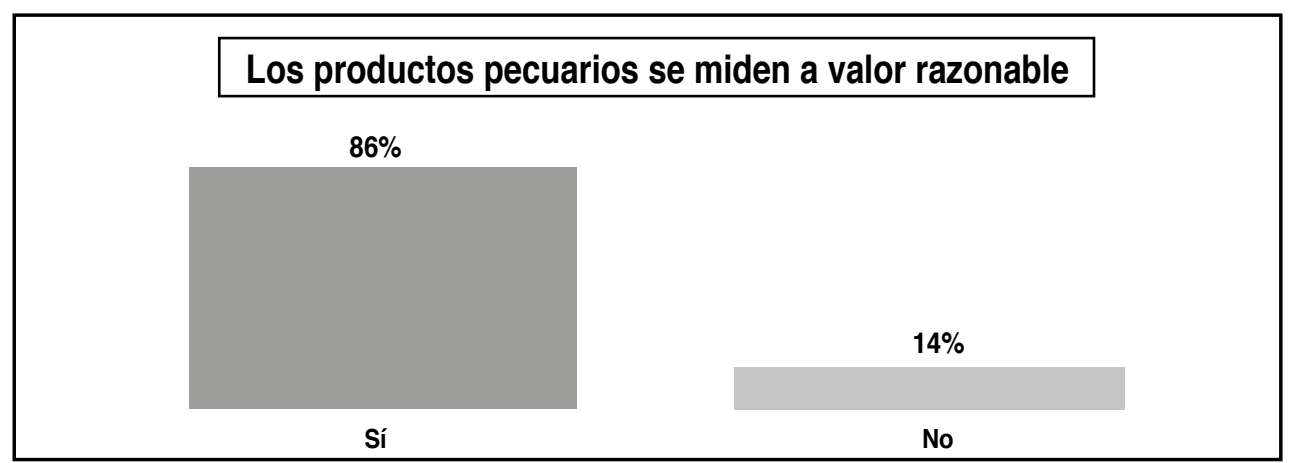

Figura 18. Productos agrícolas medidos a valor razonable

Fuente: Elaboración propia a partir de la encuesta realizada a las pymes del sector porcícola en el departamento del Quindío

Para el 86\% de las empresas del sector porcícola del departamento del Quindío, los productos agrícolas se miden a su valor razonable, para el 14\% restante no. Igualmente, el $86 \%$ de las empresas registran al costo todos los insumos necesarios para la producción y para el 14\% restante no aplica, adicionalmente el $71 \%$ de las empresas realizan la conciliación de los registros de existencias contra la contabilidad y para el resto de ellas no aplica.

Pasando al rubro de propiedad, planta y equipo, se quiso conocer a qué costo se han registrado inicialmente la propiedad, planta y equipo. (Ver Figura 19).

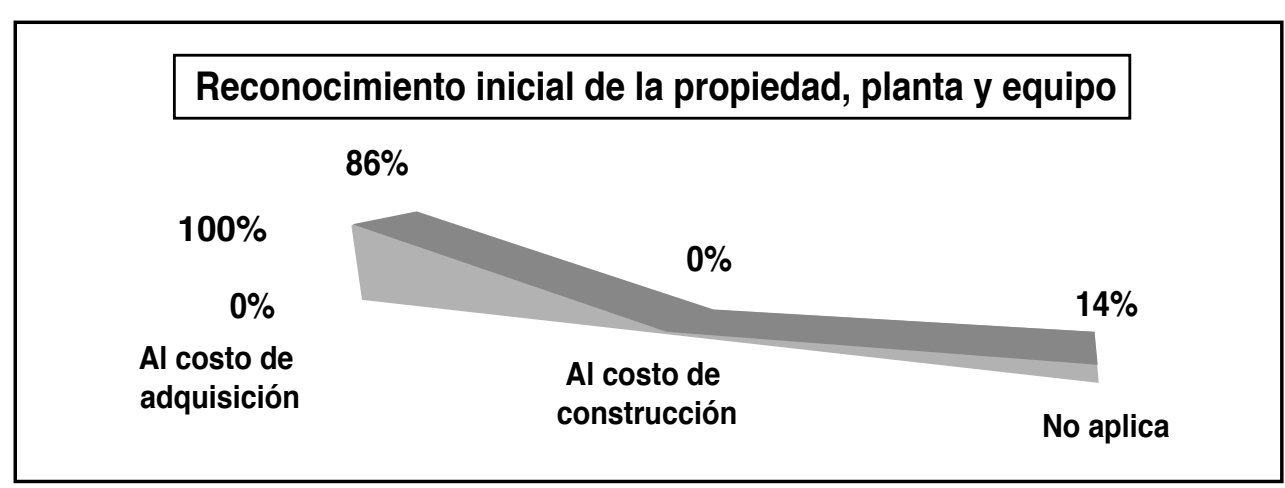

Figura 19. Reconocimiento inicial de la propiedad, planta y equipo

Fuente: Elaboración propia a partir de la encuesta realizada a las pymes del sector porcícola en el departamento del Quindío

Se comprobó que el reconocimiento inicial a la propiedad, planta y equipo se realiza al costo de adquisición para el 86\% de las empresas, para el $14 \%$ restante no aplica. En relación con los bienes aportados, donados, recibidos en pago de deuda y otros similares, se indagó si éstos se han registrado a valor razonable, encontrando que el $57 \%$ de las empresas registran este tipo de bienes a valor razonable, y para el $43 \%$ restante no aplica. Además, 
el modelo utilizado con posterioridad al reconocimiento inicial de la propiedad, planta y equipo, es el costo menos la depreciación acumulada más adiciones y mejoras, para el $71 \%$ de las empresas, para el 29\% restante no aplica.

Con respecto a los activos, se investigó acerca del tratamiento contable que las empresas les dan cuando ha habido mejoras y mantenimiento.(Ver Figura 20).

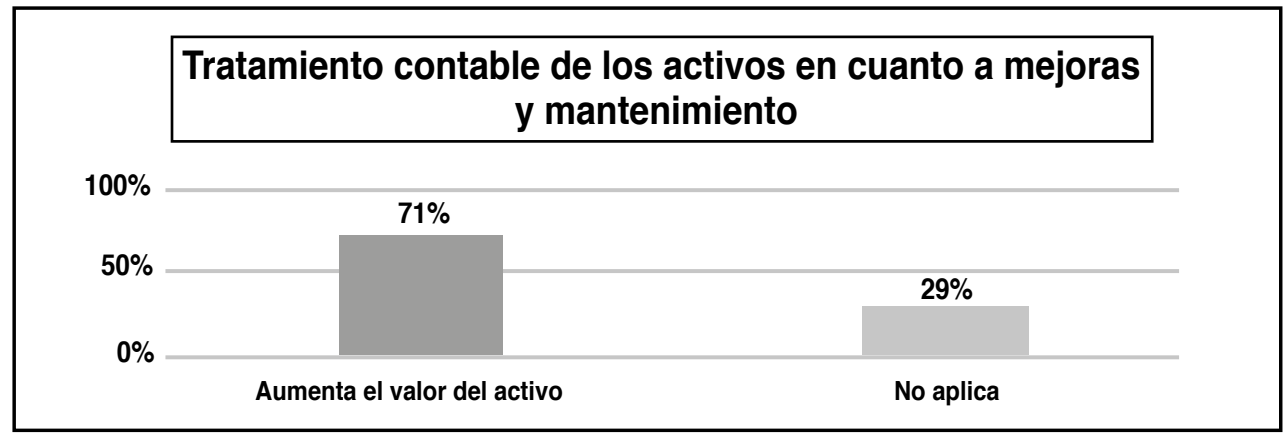

Figura 20. Tratamiento contable de los activos con mejoras y mantenimiento

Fuente: Elaboración propia a partir de la encuesta realizada a las pymes del sector porcícola en el departamento del Quindío

El 70\% de las empresas cuando hace mejoras o mantenimiento a sus activos, registran un aumento del valor del activo, para el $29 \%$ restante no aplica. En lo referente a las políticas contables que existen para la baja de activos, como se mencionó anteriormente, las empresas carecen de manual de políticas contables, Tan solo el 14\% de ellas tienen un manual, sin embargo no establecieron una política para la baja de los mismos. Es necesario tener en cuenta que todas las empresas son propietarias de los activos que poseen, y que los mismos se reconocen al costo de adquisición.

En lo referente a cuentas de control adecuadas para bienes de uso en poder de terceros, bienes de uso en tránsito, obras en curso y bienes dados de baja, se quiso conocer si esta clase de cuentas son utilizadas por las unidades empresariales del sector porcícola del departamento del Quindío, encontrándose que el $100 \%$ de las mismas no manejan este tipo de rubros. Además, se indagó si realizaban revaluación de activos, y el 86\% de las empresas manifestó que no hacen revaluación de activos, es decir que no incrementan su valor en libros y para el $14 \%$ restante no aplica.

Adicionalmente, en lo que tiene que ver con propiedad, planta y equipo, el método de depreciación utilizado por el 86\% de las empresas es el de línea recta, para el 14\% adicional no aplica. Además el $86 \%$ de las empresas estiman la vida útil de sus activos a través del método fiscal, mientras que para el $14 \%$ restante no aplica.

También se investigó si las empresas agrupan a los animales vivos y las plantas que forman parte de la actividad agropecuaria, que resultan de la gestión por parte de la entidad, de las 
transformaciones con los activos biológicos, ya sea para destinarlos a la venta o para dar lugar a otros activos biológicos diferentes. (Ver Figura 21).

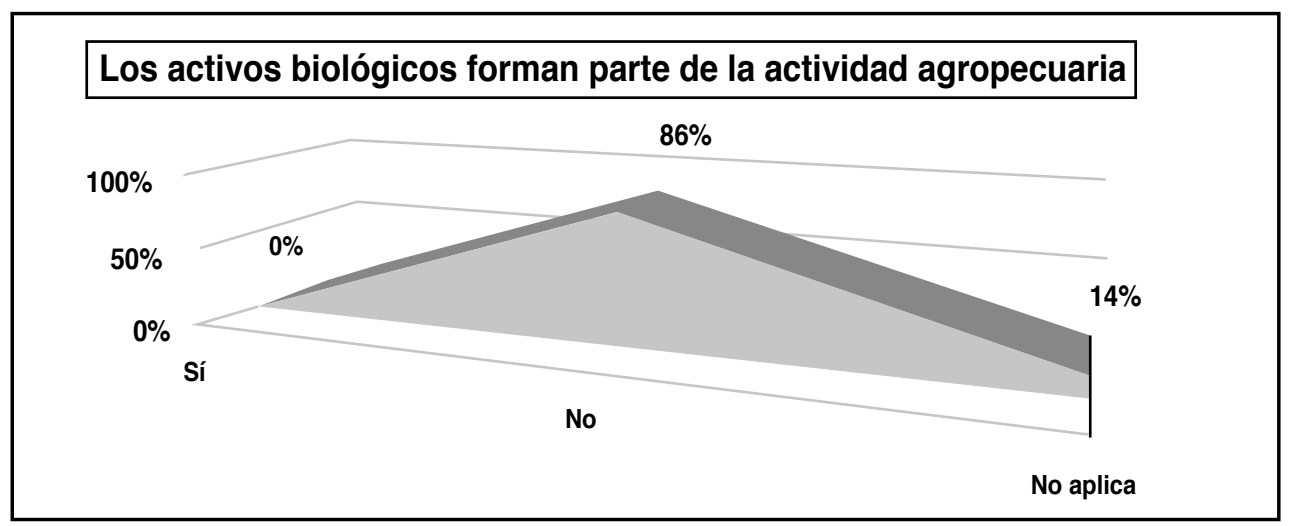

Figura 21. Activos biológicos que forman parte de la actividad agropecuaria

Fuente: Elaboración propia, a partir de la encuesta realizada a las pymes del sector porcícola en el departamento del Quindío

El 86\% de los encuestados no realizan esta acción y para el 14\% no aplica. Igualmente, en la misma proporción, los activos biológicos no se han medido al momento de su reconocimiento inicial a la fecha de cada balance, ni a su valor razonable menos los costos estimados en el punto de venta. Además, las empresas no han registrado la desvalorización de los activos cuando dicho fenómeno se ha presentado.

En relación con los activos intangibles, ninguna de las empresas del sector porcícola del departamento del Quindío posee esta clase de bienes, y en cuanto a activos diferidos el $29 \%$ de las empresas reportaron tenerlos representados en seguros y papelería, para el $71 \%$ restante no aplica.

Además se quiso conocer si las empresas agrupan las subcuentas que representan las sumas adeudadas por la empresa a los accionistas o socios, directores y gerentes y el $57 \%$ de las mismas agrupan estas subcuentas, el 14\% no lo hace y para el 29\% adicional no aplica.

En concordancia con las subcuentas que representan obligaciones por operaciones de financiación que contrae la empresa con instituciones financieras y otras entidades, por emisión de instrumentos financieros de deuda y por acumulaciones y costos financieros asociados a dicha financiación, se encontró lo siguiente (Ver Figura 22). 


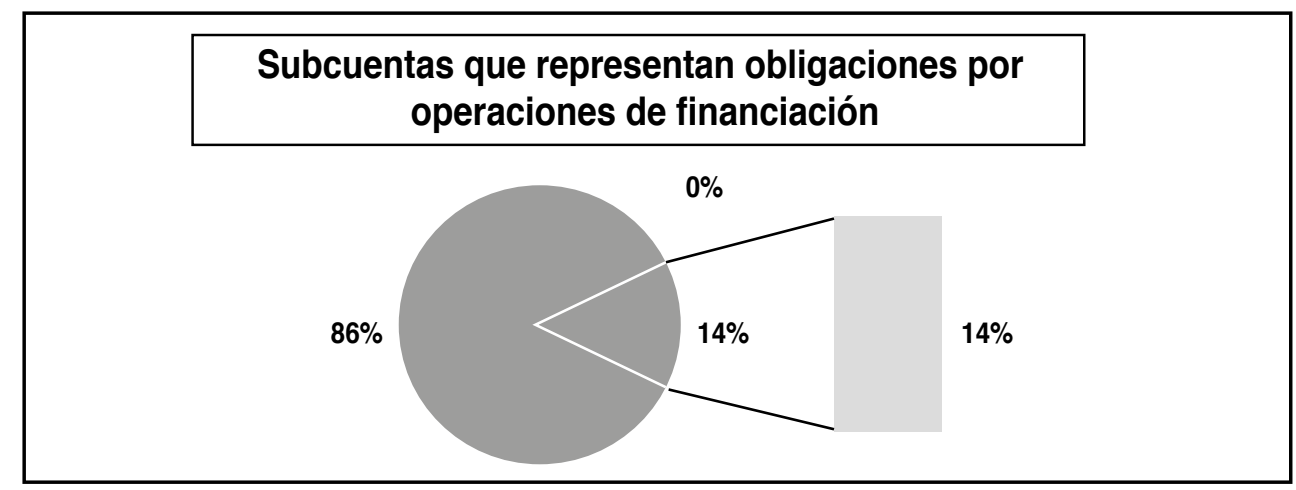

Figura 22. Subcuentas que representan obligaciones por operaciones de financiación

Fuente: Elaboración propia a partir de la encuesta realizada a las pymes del sector porcícola en el departamento del Quindío

Se observa que el $86 \%$ de las empresas agrupan las subcuentas por operaciones de financiación, y para el 14\% restante no aplica.

En correspondencia con la medición inicial del pasivo financiero a valor razonable con cambio en resultados, el $86 \%$ de las empresas han realizado este reconocimiento, mientras que para el 14\% restante no aplica. Además, en el caso de otros pasivos, el $71 \%$ de las empresas indican que en su medición inicial y posterior han sido reconocidos a su valor razonable, adicionando costos de transacción, el 14\% de ellas no realiza tal reconocimiento, para el $14 \%$ restante no aplica.

Adicionalmente se indagó a las empresas, si agrupan las subcuentas que representan cuentas por pagar a terceros por transacciones distintas a las comerciales, tributarias, laborales y financieras, a lo cual, el $86 \%$ de las mismas respondieron que no lo hacen, y para el $14 \%$ restante no aplica.

En lo referente al tema de ingresos, se consultó con las empresas si estas agrupan las subcuentas que acumulan los ingresos por ventas de bienes y/o servicios inherentes a las operaciones del giro ordinario del negocio, y el 86\% de ellas sí realizan esta práctica, y para el $14 \%$ restante no aplica.

Adicionalmente, se quiso establecer si cuando se reconocen los ingresos, éstos cumplen con las siguientes condiciones: si el monto de los ingresos se ha medido fiablemente, si la empresa ha transferido al comprador los riesgos y los beneficios de propiedad de los productos o bienes o si los costos incurridos para la generación de los ingresos pueden ser medidos fiablemente. (Ver Figura 23) 


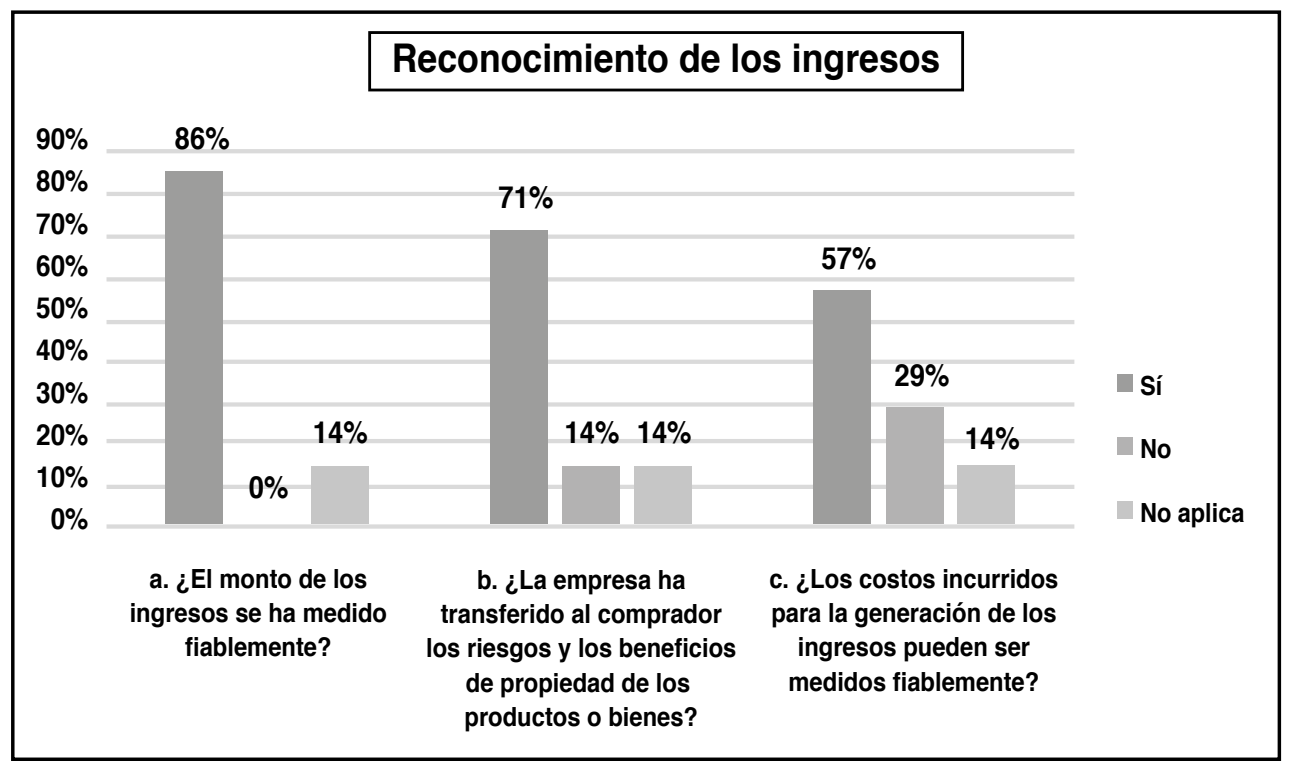

Figura 23. Reconocimiento de los ingresos

Fuente: Elaboración propia, a partir de la encuesta realizada a las pymes del sector porcícola en el departamento del Quindío

El 86\% de las empresas afirmaron que el monto de los ingresos se ha medido fiablemente, para el 14\% restante no aplica. Asimismo, el 71\% de los encuestados han transferido al comprador los riesgo y los beneficios de propiedad de los productos o bienes, el 14\% no y para el 14\% adicional no aplica. Por último, el 57\% de las empresas afirmaron que los costos incurridos para la generación de ingresos pueden ser medidos fiablemente, para el $29 \%$ no, y para el otro $14 \%$ no aplica.

Se pretendió conocer lo que piensan los encuestados en cuando a si es probable que los beneficios económicos relacionados con las transacciones, fluirán a la empresa, y el 100\% de ellas consideran que hay una gran probabilidad de que los beneficios económicos en razón de las transacciones que manejan harán fluir la misma.

En relación con las políticas que tienen las empresas para ofrecer descuentos, se halló que los mismos se realizan cuando hay mayor cantidad de grasa en los porcinos, que a su vez viene a ser una política de garantía, pero solo la aplican el $29 \%$ de las empresas y para el $71 \%$ restante no aplica.

Para finalizar se solicitó a las pymes enumerar las cuentas que conforman su patrimonio. (Ver Figura 24). 


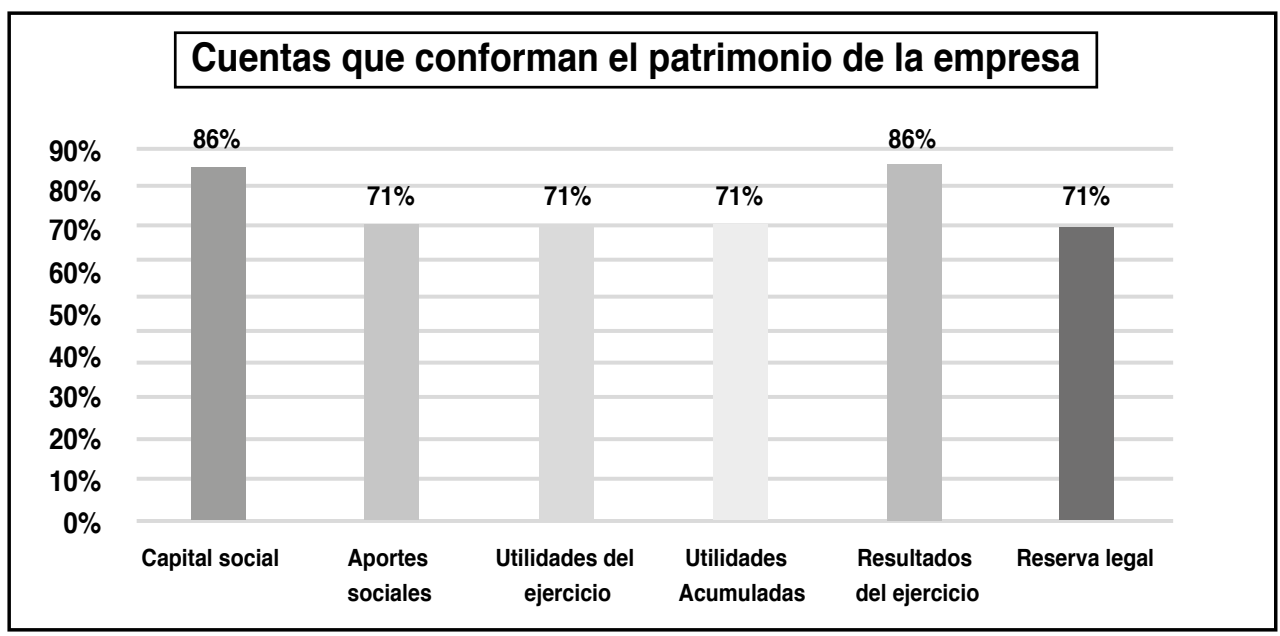

Figura 24. Cuentas que conforman el patrimonio

Fuente: Elaboración propia, a partir de la encuesta realizada a las pymes del sector porcícola en el departamento del Quindío

Las empresas en su patrimonio manejan diferentes cuentas, tales como el $86 \%$ de ellas capital social, el $71 \%$ aportes sociales, el $71 \%$ utilidades del ejercicio, el $71 \%$ utilidades acumuladas, el $86 \%$ resultados del ejercicio y por último el $71 \%$ reserva legal.

\section{Conclusiones}

El objeto de las pymes del sector porcícola en el departamento del Quindío está dirigido a la producción de lechones para su venta, desde su nacimiento hasta lograr un peso estimado para su comercialización (ciclo completo). Además, algunas de las empresas porcícolas usan esta actividad como apalancamiento del flujo de efectivo de otras actividades como el café.

Como temas a destacar en el área administrativa y contable, se tiene que las empresas del sector porcícola del departamento del Quindío son empresas relativamente jóvenes, también un dato positivo es el hecho de que aunque no todas esta obligadas a llevar contabilidad, la mayoría lo hacen y consideran que es un área importante para su crecimiento y desarrollo. Además, como se mencionó anteriormente, son estructuras organizacionales de poca complejidad por lo que en la mayoría de ellas se encontró que no poseen un software contable y llevan su contabilidad en libros físicos.

Contablemente, solo un $14 \%$ de las empresas tiene implementado un manual de políticas contables y la autoridad que avala las mismas es el administrador de la empresa. Además, se encontraron deficiencias importantes en las mediciones iniciales y posteriores de las partidas, y en todo lo que tiene que ver con la clasificación de las mismas, lo que muestra contabilidades muy poco fiables y que no podrían emplearse como instrumento certero para la toma de decisiones. Además, el sector presenta una estructura organizacional poco compleja, sin inversiones, sin vinculados económicos y en la mayoría de los casos con financiación propia. En conclusión, los estados financieros de las empresas del sector 
porcícola del departamento del Quindío no cumplen con los requerimientos del anexo del Decreto 3022 de 2013 NIIF para pymes.

Aunque se ha crecido a nivel de infraestructura y tecnificación, todavía se encuentran muchas deficiencias de orden administrativo. Algunas empresas no cuentan con todos los documentos necesarios para su funcionamiento, por lo que podrían estar expuestas a posibles multas y sanciones.

Las empresas en su mayoría conocen de la entrada en vigencia de la Ley 1314 de 2009, sin embargo manifiestan que ninguna Superintendencia les ha exigido la implementación de las normas, pese a que nuestro país ha adoptado la estandarización de un lenguaje contable y financiero internacional y su ejecución es de obligatorio cumplimiento.

La mayoría de las empresas cuentan con la certificación de calidad BPG (Buenas Prácticas Ganaderas) que otorga el ICA (Instituto Colombiano Agropecuario) a los ganaderos por ofrecer productos con garantía sanitaria y de inocuidad que no generan riesgos para la salud humana.

\section{Conflicto de intereses}

Los autores declaran no tener ningún conflicto de intereses.

\section{Referencias bibliográficas}

1. Arizabaleta, E. V. (2000). Diagnóstico organizaional. Evaluación sistemáica del desempeño empresarial en la era digital. ECOE.

2. Cámara de Comercio.(2016). Base de datos. Armenia.

3. Consejo Técnico de la Contaduría Pública. (2012). Documento Direccionamiento estratégico.

4. DANE. (2003). Primer censo porcícola. Bogotá D.C.

5. DANE. (02 de Septiembre de 2005). www.dane.gov.co.

6. Decreto Reglamentario 3022 de 2013.

7. Gobernación del Quindío. (2008). Plan Regional de Competitividad Quindío 2032. Armenia.

8. Gobernación del Quindío. (03 de agosto de 2015). Gobernación del Quindío. Obtenido de http://quindio.gov.co/el-departamento/generalidades/datos-geograficos-basicos.html

9. Ley 1314 de 2009.

10. Ley 905 de 2004.

11. Márquez, G. D. (2001). Administración integral en la empresa. Ciudad de México: Trillas.

12. Proyecto de investigación (2016).Caracterización de la implementación por primera vez de las Normas Internacionales de Información Financiera (NIIF) para pymes en las empresas del sector agropecuario del departamento del Quindío.

13. Salvador, V. R., \& Ofelia, A. M. (1998). diagnóstico empresarial. Método para identificar, resolver y controlar problemas en las empresas. Ciudad de México: Trillas.

14. Sergio, R. (2007). herramientas de gestión: Diagnóstico empresarial. Fruticultura \& diversificación, 9. 